\title{
Effect of Addition of Skim Milk in Tea To The Activity of Antioxidant Tea
}

\author{
Kristina Simanjuntak ${ }^{l}$, An'umillah $\mathrm{AZ}^{2}$, Lasma Nurhayati ${ }^{3}$ \\ Biochemistry Department of Medicine Faculty Universitas Pembangunan Nasional (UPN) \\ Jakarta \\ Email.kristin_juntak@yahoo.com
}

\begin{abstract}
Tea drinks are often used daily, and good for health because they contain antioxidants. This drink is often mixed with milk, and tastes so delicious, but the levels of tea antioxidants are reduced. The purpose of this study was to determine the effect of additional skim milk on tea antioxidant activity. This research was conducted in vitro laboratory experiments with black tea, green tea and white tea samples with $1 \mathrm{~g} / 100 \mathrm{ml}$ content. The sample was taken $200 \mu \mathrm{l}$ and mixed with skim milk with volume $1,1.5$ and $2 \mathrm{~mL}$, then tea antioxidant activity was tested by 1,1diphenyl-2-picrilhidrazil (DPPH) method and measured its activity using spectrophotometer with $\lambda=517 \mathrm{~nm}$. One way Anovayield, there is influence of addition of milk between volume $1,1.5$ and $2 \mathrm{ml}$ to antioxidant activity of white tea and black tea $(p=0.000)$, meaning decrease of antioxidant activity after added with milk. Antioxidant activity (\% inhibition) of white tea is higher $84.39 \%$ than black tea is $73.54 \%$. The addition of milk into tea can reduce the antioxidant activity, because proteins milk interact strongly with the antioxidants polyphenols from tea.
\end{abstract}

Keywords: white tea; black tea; skim milk; antioxidant activity

\section{INTRODUCTION}

Tea (Camellia sinensis)contains polyphenol compounds that are antioxidants such as flavan-3-ol, phenolic acids, flavonols and flavones, catechins, teaflavin, tearubigin, teasinensin and teabrownin. Based on its processing the tea is classified into fermented tea such as black tea, semi fermented such as oolong tea and without fermentation such as white tea, yellow tea and green tea[1,11].

Black tea contains gallic acid, acid ester kuinat, teogallin, teaflavin and gallic acid tearubigin is increasing due to oxidation of the phenolic esters during fermentation. Teaflavin gives a yellowish red color and gives a sense of pleasure[1,2,3].

The antioxidant activity of teaflavin differs from catechins. Teaflavin is able to withstand superoxide radical attacks at 10 -fold speeds that are much more efficient than epigallokatekingallic(EGCG). Catechins most commonly found in green tea consisting of EGCG, epicatechin-3 gallic (ECG), epigallocatechin (EGC), epicatechin (EC), catechin (C) and gallokatekingallic (GCG). EGCG has a greater ability to protect. The antioxidant strength of epigallokatekin is greater than that of epicchinekingallate and greater than catechins. The ability of antioxidant activity is influenced by the number of hydroxyl groups polyphenols in tea[1,5,7].

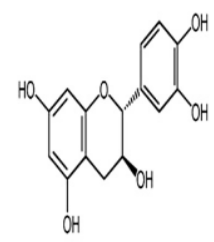

Catechin<smiles>O=c1c(O)c(-c2ccc(O)c(O)c2)oc2cc(O)cc(O)c12</smiles>

Quercetin

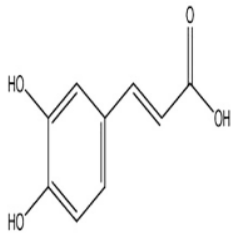

Caffeic acid<smiles>O=C(O)c1cc(O)c(O)c(O)c1</smiles>

Gallic acid

Fig.1. Flavonoid structure in tea
Many tea drinks in the market, there is a mixture of tea with milk such as milk tea, Thai tea, green tea, green tea latte, matcha ice cream and provide a more delicious flavor. Polyphenols are efficacious for health, highest in green tea then oolong, followed by black tea. Green tea contains more than $36 \%$ of polyphenols catechins, although this amount is still influenced by weather, varieties, soil types and maturity levels[1,4,5,6].

Efficacy of tea depends on polyphenols contained in many young tea leaves. Flavonol is a major antioxidant substance in tea leaves that is quercetin, kaempferol and mirisetin, about 2- 3\% part of water-soluble tea is a flavonol compound. Determine the antioxidant ability of tea and skim milk mixture in tea can influence antioxidant activity, so it can give benefit to society not to mix milk with tea. Polyphenolic compounds in tea can bind to the casein milk which causes the antioxidant activity of the tea in vitro decreases[4,6,7,21].

\section{MATERIAL AND METHODS}

Material, White tea (heaven leaf), black tea (Tong Tji), skim milk (greenfield), methanol (p.a), aquadest, DPPH (1,1diphenyl-2-picrylhydrazyl). Sample is white tea and black tea at concentration $1 \mathrm{~g} / 100 \mathrm{ml}$,heated at boiling temperature and mixtured of tea solution with skim milk with volume $1,1.5$ and $2 \mathrm{ml}$. Antioxidant capacity examination by 1,1-diphenyl- 
2-picrylhydrazyl (DPPH) method, whose activity antioxidant using spectrophotometer with wavelenght517 nm.

\section{RESULT \& DISCUSSION}

Antioxidant activity with DPPH method yield, white tea are yield $84,39 \%$ and black tea equal to $73,54 \%$. Tea antioxidant levels can use the DPPH method, because free radicals DPPH that are stable interacting with hydrogen from tea polyphenols to form color change from colordark purple until it becomes purple yellow to disappear at a wavelength of 517 $\mathrm{nm}[20,21,22]$. The change is due to a decrease in absorptivity of DPPH molecules(fig. 2).

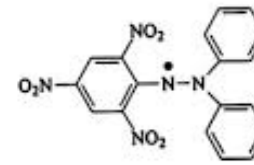

DPPH Radikal (ungu)

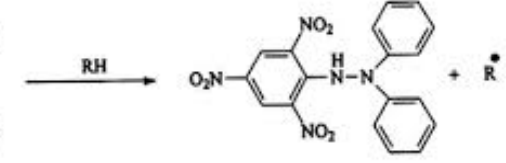

DPPH Stabil (kuning)
Fig.2. Stable free radical diphenylpicrylhydrazyl (DPPH) for estimating antioxidant activity

One way Anovayield, there is influence of addition of milk between volume $1,1.5$ and $2 \mathrm{~mL}$ to antioxidant activity of white tea and black tea $p_{\text {value }} 0.000$.Decreased antioxidant activity after added with milksuch as fig. 3 and fig.4.Post Hoc Bonferroni test $p_{\text {value }} 0.000$, there is influence between antioxidant activity of infusa black tea without mixture with group.

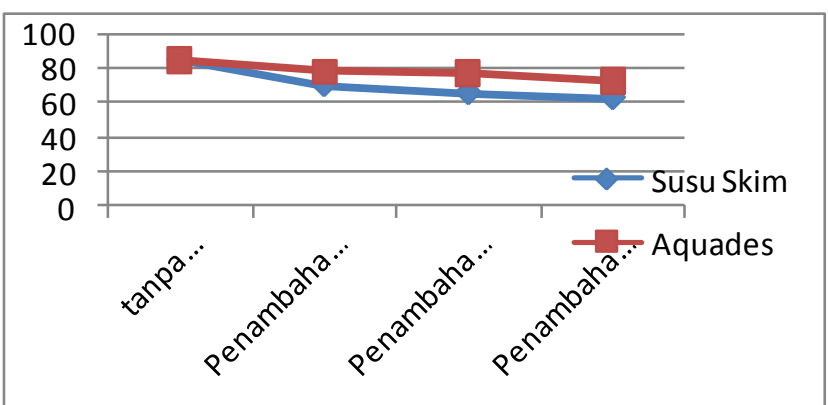

Fig.3. Activity antioxidant of white tea with DPPH method

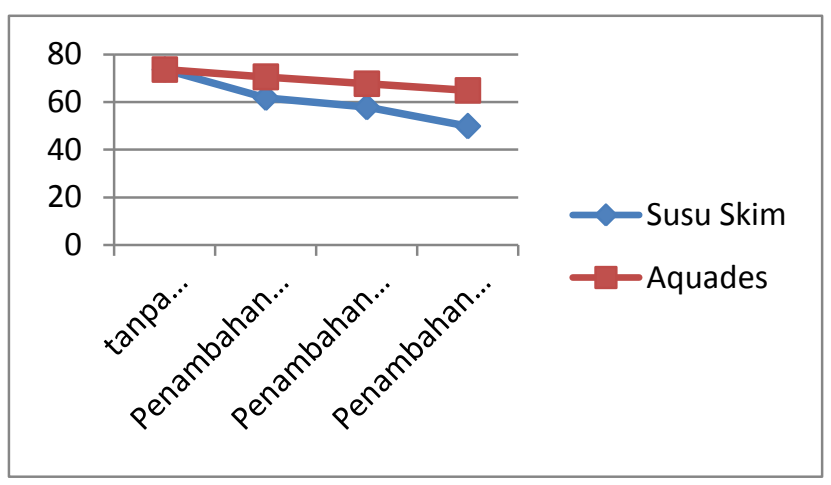

Fig.4. Activity antioxidant of black tea with DPPH method
Differences in antioxidant activity caused by the processing black tea undergoes a fermentation process that results in catechin changes to gallic acid, whereas in white tea the content of catechins is higher so that the antioxidant properties in white tea is higher than the black[1,12]. White tea is a tea obtained from non-fermented processed with a higher number of catechins. The antioxidant polyphenol catechins present in white tea are higher than the antioxidants of gallic acid in black tea[4,14,16].

The effect of tea antioxidant activity decreased after addition of skim milk into the black tea tea because of the linking link of milk protein to polyphenols from tea. ${ }^{11}$ Antioxidant activity in black tea infusa with cow's milk decreased by $7-25 \%$ when compared with black tea infusa without mixture[11,12]. Skim milk, its antioxidant activity is lower than that of fresh milk and semi-skimmed milk[15]. Polyphenols in tea can bind to milk proteins and cover the active groups on polyphenols so that polyphenols can not optimize their radical capture capacity[12,18]. Casein milk has a stronger affinity binding to tea polyphenols than whey proteins $[4,5,8]$ Tea polyphenols have the ability to interact with milk proteins especially proline-rich proteins such as casein. The proline group in casein protein has a strong affinity for the hydroxyl groups in polyphenols, since casein has the greatest effect on the decrease in tea antioxidant activity than other proteins in milk[4,5,6,11]

Decreased antioxidant activity in tea mixes with milk because interaction between casein and polyphenol resulting in decreased tea antioxidant activity while the distilled water in the control solution did not bind to polyphenols so decreased antioxidant activity in the control solution due dilution effect by the distilled water[14,15,17]. The affinity of polyphenol bonds to proteins depends on the size of the polyphenol molecule, meaning the stronger the affinity for larger molecules of polyphenols. Polyphenols with larger molecules such as theaflavin in black tea are easier to form complex and bind to proteins. The bond will reduce the number of available hydroxyl groups and reduce the capacity of polyphenol electron donors thereby decreasing greater antioxidant activity in black tea than white tea[10,13,15,17]. Black tea processing takes place oxidation by polyphenol oxidase enzymes that convert catechins into theaflavins and thearubigins that have large polyphenol structures so that black tea has a lower catechinmore than green tea content and theaflavin and tearubigine higher[13,18]. White tea is a nonfermented tea that does not go through the process of oxidation in its productionWhich has higher catechin content and theaflavin and thearubigin lower[1,14,17]. 


\section{CONCLUSION}

There was a significant effect of antioxidant activity of black tea and white tea with tea mixture with skim milk with DPPH method with $\mathrm{p}_{\text {value }} 0.000$. White tea antioxidant activity $84.39 \%$ higher than black tea $73.54 \%$. The antioxidant affinity of tea mixed with skim milk has decreased significantly because polyphenols are oxidized by oxygen from the amino acid side chains of milk at an alkaline $\mathrm{pH}$, causing crosslinking of tea proteins to form highly irreversible quinines reactive and react with sulfhydryl groups of proteins that affect the capacity of polyphenol electron donation and decrease the antioxidant activity of tea.

\section{REFERENCES}

[1] Agnieszka,Kosińska,Wilfried,and Andlauer, "Antioxidant Capacity of Tea: Effect of Processing and Storage,'Division of Food Sciences, Poland University Switzerland. 2014

[2] Silva, BM, Oliveira, P. F. Dias, T. R.Tomás, G. Teixeira, N. and F.Alves, M. G, "White Tea (Camellia Sinensis (L.): Antioxidant Properties and Beneficial Health Effects," J.of Food Sci.Nutr. and Dietetics, 2013,vol 2, p. 1-15.

[3] YunSheng W, et.all, "Functional analysis of flavonoid 3',5'-hydroxilase from tea plant (Camellia sinensis), Critical role in the accumation of cathecin," BMC Plant Biologi China, 2014, 14, pp.1-14

[4] Bourassa, P.Côté, R.Hutchandani, S. Samson, G.and Tajmir-Riahi, H, 'The effect of milk alpha-casein on the antioxidant activity of tea polyphenols', J. Photochemistry and Photobiology B: Biology, 2013, vol128, pp.43-49

[5] Xiao, J, Mao, F, Yang, F, Zhao, Y, Zhang, C, and Yamamoto, K, "Interaction of dietary polyphenols with bovine milk proteins: Molecular structureaffinity relationship and influencing bioactivity aspects," Molecular Nutrition \& Food Research, 2011,vol55, pp.1-9.

[6] Hasni, I, Bourassa, P, Hamdani, S, Samson, G,Carpentier, $\mathrm{R}$, Tajmir-Riahi, H, 'Interaction of milk a- and bcaseins with tea polyphenols', Food Chemistry, 2012,126,p. 630-639.

[7] Mirzaei, A \&Mirzaei, M, 'The Effect of Adding Milk on Antioxidant Activities of Green and Black Tea', Bulletin of Environment, Pharmacology and Life Science, 2013, pp 37-42.

[8] Monica G, Giovanni V, Givlia G, Carmelia DS, Pasquale $\mathrm{F}$, The interaction of cocoa polyphenol with protein srudied by proteomic techniques, J.Food Research International, 2013, 54, pp.406-415

[9] Kanakis, CD, Hasni, I, Bourassa, P, Tarantilis, PA, Polissiou, MG, Tajmir-Riahi, H, 'Milk b-lactoglobulin complexes with tea polyphenols," Food Chemistry, 2011, 127, pp.1046-1055.

[10] Gramza, A, Korczak, J.Amarowicz, R, 'Tea polyphenoltheir antioxidant properties and biological activity", A
Review, Polish J. Food and Nutrition Sciences, 2005, vol.14, pp. 219-235.

[11] Haratifar, S, "Nanoencapsulation of Tea Catechins in Casein Micelles: Effects on Processing and Biological Functionalities,'Tesis, The University of Guelph.

[12] Hilal, Y,andEngelhardt, U, “Characterisation of white tea - Comparison to green and black tea,"J. Consumer Protection and Food Safety, 2007,vol. 2, pp. 414-421.

[13] Langley-Evans, SC, "Consumption of black tea elicits an increase in plasma antioxidant potential in humans. International Journal of Food Sciences and Nutrition, 2009, vol.51, pp. 309-315.

[14] Ryan, L,and Petit, S, 'Addition of whole, semiskimmed, and skimmed bovine milk reduces the total antioxidant capacity of black tea', Nutrition Research Journal, 2009, pp. 14-20.

[15] Lorenz, M, Jochmann, N, Von Krosigk, A, Martus, P, Baumann, G, Stangl, K, and Stangl, V, "Additionof milk prevents vascular protective effects of tea," European Heart journal, 2007,vol.28, pp.219-223.

[16] Sharma, V, Vijay K.H, and Jagan, M.R.L, "Influence of milk and sugar on antioxidant potential of black tea', Food Research International, 2008.vol.41, pp. 124-129.

[17] Ye, J, Fan, F, Xu, X, and Liang, Y, "Interaction of Black and Green Tea Polyphenols with Whole Milk," Food Research International, 2013, vol. 53, pp 449-455.

[18] Yuksel, Z, Avci, E, and Erdem, Y.K, "Characterization of Binding Interactions between Green Tea Flavanoids and Milk Proteins," Food Chemistry, 2009, vol.121, pp. 450-456.

[19] Yashin, A, Yashin, Y, Nemzer, B, "Determination of Antioxidant Activity in Tea Extracts, and Their Total Antioxidant Content," American Journal of Biomedical Sciences, 2011,vol 3, pp. 322-335.

[20] Apak, R, Gorinstein, S, Bohm, V, Schaich, K.M, Ozyurek, M, and Guclu, K, "Methods of measurement and evaluation of natural antioxidant capacity/activity (IUPAC Technical Report)," Pure and Applied Chemistry, vol. 85, 2013, pp.957-998.

[21] Molyneux, P,'The use of the stable free radical diphenylpicrylhydrazyl (DPPH) for estimating antioxidant activity,"SongklanarinJ. Science and Technology, 2005, vol.26, pp. 212-219. 